УДК 504.5:631.4:550.4-032.1

\title{
ГЕОХИМИЧЕСКАЯ ХАРАКТЕРИСТИКА ПОЧВ ТЕРРИТОРИИ С ВЫСОКОЙ АЭРОТЕХНОГЕННОЙ НАГРУЗКОЙ
}

\author{
Воробьёва Дарья Андреевна ${ }^{1}$, \\ vorobeyda18@gmail.com

\section{Гусева Наталья Владимировна ${ }^{1}$,} \\ gusevanv@tpu.ru \\ 1 Национальный исследовательский Томский политехнический университет, \\ Россия, 634050, г. Томск, пр. Ленина, 30.
}

\begin{abstract}
Актуальность исследования обусловлена тем, что почва, являясь связующим звеном между геосферами Земли, играет важнейшую роль как в экономическом, так и в социальном развитии территорий. Почвы имеют большое экологическое значение, выходящее далеко за сельскохозяйственные рамки, и при этом часто находятся под влиянием техногенных факторов, способных привести к изменению течения геохимических процессов (как, например, на Кольском полуострове, где сконцентрированы купные горнодобывающие и металлургические предприятия). Поэтому встает вопрос о различии геохимических характеристик почв, в том числе фрракционного состава соединений химических элементов, техногенно-трансформированных и фоновых территорий.

Цель: оценка геохимической специфики почв, в том числе фракционного состава соединений химических элементов, территории с высокой аэротехногенной нагрузкой.

Объекты: почвы территории с высокой аэротехногенной нагрузкой (район водосбора озера Имандра, Мурманская область). Методы. Фракционный состав соединений химических элементов в почвах определялся методом последовательных селективных вытяжек из одной навески. Химический анализ вытяжек проводился с использованием масс-спектрометра с индуктивно-связанной плазмой (ICP-MS). Минералогический состав почв изучался методами рентгенофразового анализа и электронной микроскопии.

Результаты. Исследования показывают, что большинство химических элементов остается связано в остаточной фрракции. Однако на рассматриваемой территории основная доля редкоземельных элементов - Na, Rb, Sb, Zr, Pb u U - связана с органическим веществом. Влияние выбросов медно-никелевого комбината отражено в увеличении концентрации меди и никеля в иллювиальном горизонте почв, присутствии микроминеральных фаз оксидов никеля и меди и соединений редкоземельных элементов, а также в увеличении в доли подвижных фоорм $\mathrm{Ni} \mathrm{u} \mathrm{Cu}, \mathrm{Cr}, \mathrm{Co}, \mathrm{Cd}, \mathrm{As}, \mathrm{Sb}$.
\end{abstract}

\section{Ключевые слова:}

Фракционирование, селективные вытяжки, почва, аэротехногенная нагрузка, Кольский полуостров.

\section{Введение}

В экосистемах различного масштаба все компоненты связаны между собой потоками вещества и энергии, что обеспечивает цикличность процессов, устойчивость экосистем во времени и высокое качество природных сред. Однако эти же самые процессы способствуют и распространению материальных загрязнителей со всеми вытекающими для экосистем последствиями. Влияние антропогенных факторов может приводить к нарушению естественных потоков и перераспределению химических элементов в компонентах окружающей среды [1-3].

Почва является узлом экологических связей всех приповерхностных геосфер Земли. Она наделена многочисленными глобальными функциями, деградация которых может обернуться для цивилизации самыми тяжелыми последствиями [4]. Экологическое значение почвы выходит далеко за рамки сельскохозяйственных работ. Установлено, что почва является биогеохимическим барьером для проникновения «аэротехногенных» тяжелых металлов в подземную гидросферу [5]. При длительном воздействии происходит снижение сорбционных свойств почвы и ее деградация. Подобная проблема отмечается в районах влияния горнометаллургических заводов во Франции, США, Канаде, Иране, Южной Корее, Китае и др. [6-10].
При поступлении загрязняющих веществ, например тяжелых металлов, с атмосферными осадками определяющим будет их поведение и перераспределение в почвенном горизонте. Процессы осаждения или вторичного высвобождения химических элементов будут оказывать влияние на состояние других компонентов окружающей среды. Решающая роль в распределении, миграции и концентрировании химических элементов принадлежит не столько их валовому содержанию, сколько формам нахождения химических элементов в природных объектах. В результате длительного антропогенного воздействия происходит не только значительное обогащение почв загрязняющими элементами, но и меняется их соотношение в различных формах [11].

В геохимии, геологии, геоэкологии и почвоведении используются различные методы и приемы оценки форм нахождения элементов в горных породах, донных осадках и почвах, среди которых основными являются методы химического фракционирования, в том числе последовательная экстракция из одной навески [12]. Метод постадийных вытяжек нашел применение при изучении структуры геохимических полей, геохимических поисках полезных ископаемых, изучении геохимии почвенного покрова, определении 
геохимических аспектов техногенного воздействия и охраны окружающей среды [12-17].

Выявление форм нахождения микроэлементов в почвах позволяет охарактеризовать особенности распределения элементов в почвенных разрезах, находящихся в естественном либо измененном под техногенным воздействием состоянии. Кроме этого, соотношение форм нахождения химических элементов в почвах определяет способность почвы выполнять ее основные экологические функций и как природного тела, и как источника плодородия и защиты природных сред от загрязнения, а также определяет влияние почв на сопредельные геосферы [11].

Целью работы является выявление особенностей соотношения форм нахождения химических элементов в почвах территории с высокой аэротехногенной нагрузкой.

\section{Объект и методы исследования}

Район исследования. Районом исследования является западная часть территории водосбора озера Большая Имандра в центральной части Мурманской области (Кольский полуостров, северо-запад России) В геологическом отношении район исследования располагается в пределах восточной части Балтийского щита, сложенного породами кристаллического фундамента, перекрытыми рыхлыми четвертичными отложениями. Территория представляет собой холмистую равнину с участком техногенной пустоши. В геологическом строении здесь принимают участия основные и ультраосновные породы, перекрытые моренными озерно-ледниковыми и флювиогляциальными отложениями [18].

Климат умеренно-холодный, со среднегодовым количеством осадков и температурой 553 мм и $-0,8^{\circ} \mathrm{C}$ соответственно. Преобладающее направление ветра - с севера на юг летом и с юга на север зимой. Основной тип почвы подзолистые. На Кольском полуострове типичны подзолы малой мощности - 15-50 см [19]. Для подзолов характерен дифференцированный профиль, состоящий из подстилки толщиной 3-8 см, беловатого, осветленного за счет удаления красящих соединений железа и перегноя подзолистого или элювиального горизонта (Е) толщиной от 2 до 20-30 см; иллювиального горизонта коричневых или охристых тонов (В), образовавшегося в результате иллювиального накопления алюминиево-железисто-гумусовых комплексных соединений, постепенно переходящего в материнскую породу (С) [20].

На исследуемой территории расположено одно из крупнейших промышленных предприятий Мурманской области - медно-никелевый комбинат «Североникель» (Кольская горно-металлургическая компания, построен в 1930-е гг.), находящийся в Мончегорске. Выбросы Кольской горно-металлургической компании (в совокупности от предприятий «Североникель» в Мончегорске и «Печенганикель» в городах НикельЗаполярный) снизились с 1627,1 т в 1998 г. до 348,9 т в 2017 г. для никеля, с 1062,2 до 486,9 т для меди за тот же период. В настоящее время на комбинате в Мончегорске перерабатывается медно-никелевый штейн и завершается технологический цикл производства товарной продукции компании [2].

Материаль и аналитические методы. В соответствии с преобладающим направлением ветра во время полевых исследований летом 2016 г. было проведено погоризонтное опробование почв. Точки опробования расположены по мере удаления от источника пылегазовых выбросов (комбината «Североникель»).

Для оценки накопления тяжелых металлов в разных типах почв особое значение имеет структура их вертикального профиля (от поверхности почвы до материнской породы). Как правило, почвенный профиль состоит из нескольких слоев, называемых генетическими горизонтами, поскольку они образовались в результате почвообразовательных процессов, обусловленных генезисом почвы [20]. Сочетание различных горизонтов определяет характер накопления, миграции и перераспределения химических элементов, в том числе загрязняющих веществ, по почвенному профилю.

Для исследования были выбраны два почвенных разреза, относящихся к подзолистому типу почв:

- пункт опробования СП-8 (N 67²52'22,8" Е $32^{\circ} 47^{\prime} 11,59^{\prime \prime}$ ) расположен в 7 км в южном направлении от медно-никелевого комбината (у родника «Габбрский»). Верхний горизонт О эродирован, далее подзолистый горизонт Е (глубиной 1-8 см) и иллювиальный горизонт В (8-24 см).

- пункт опробования СП-10 (N 67051'14,68" Е $32^{\circ} 47^{\prime} 54,42^{\prime \prime}$ ) расположен в 15 км в южном направлении от комбината. Почвенный профиль представлен подстилкой O (0-4 см); подзолистым горизонтом Е (4-10 см); иллювиальным горизонтом, который по степени выраженности признаков подразделятся на горизонты В1 (10-17 см) и В2 (17-24 см); горизонтом C (24-48 см). Растительность представлена елью, березой, черникой, вороникой.

Образцы почвы, высушенные естественным путем на воздухе, просеивались через сито с диаметром пор 1 мм для удаления крупных корней растений и гравийного материала. Для определения общей концентрации металлов небольшую порцию каждого образца почвы взвешивали, помещали в полипропиленовый сосуд разложения, а затем обрабатывали $\mathrm{HNO}_{3}$ в микроволновой печи. Концентрации химических элементов определяли с использованием массспектрометра с индуктивно связанной плазмой NexION 300 (Perkin-Elmer, США) в аккредитованной проблемной научно-исследовательской лаборатории гидрогеохимии ТПУ.

Определение фракционного состава соединений химических элементов в почвах проводилось методом последовательных селективных вытяжек по R. McLaren и D. Crawford [21] с изменениями Д. Ладонина [22].

В основе этого метода лежит применение экстрагирующих растворов, разрушающих в почвенном образце определенный тип химической связи элементов с твердофазными компонентами или сам компонент, после чего в раствор переходят химические элементы, входящие в одну группу соединений или фракцию [22]. 
Были выделены следующие шесть фракций [22, 23]:

I. Водорастворимая фракиия является легкодоступным источником питания растений и представлена свободными ионами или комплексными соединениями.

II. Обменная фракиия - поведение химических элементов определяется процессами ионного обмена. Эта фракция выделяется экстрагированием $0,05 \mathrm{M}$ $\mathrm{Ca}\left(\mathrm{NO}_{3}\right)_{2}$ за счет разрушения слабых электростатических взаимодействий, удерживающих химические элементы.

III. Специфически сорбированная фракиия выделяется 2,5\% раствором уксусной кислоты. Сюда относится вся совокупность химических элементов, удерживаемая почвенными компонентами за счет связей, отличных от ионной (то есть необменно), например, при закреплении на дефектах кристаллических решеток.

$I V$. Фракция, связанная с органическим веществом, выделяется путем его разрушения $\mathrm{K}_{4} \mathrm{P}_{2} \mathrm{O}_{7}$ в щелочных условиях ( $\mathrm{pH} 11)$.

V. Фракиия, связанная с оксидами и гидроксидами железа и марганиа, выделяется с помощью реактива Тамма при облучении ультрафиолетом при $\mathrm{pH}$ 3,3 и включает химические элементы, образующие прочные комплексы на поверхности железомарганцевых конкреций.

VI. Остаточная фракиия содержит химические элементы, прочно закрепленные в кристаллических решетках минералов почвы, которые невозможно извлечь применением перечисленных выше экстрагентов. Выделяется путем разложения остатка $\mathrm{HNO}_{3}$ в микроволновой печи.

Для экстракции навеску помещают в центрифужные пробирки и добавляют экстрагирующий раствор (соотношение почва:экстрагирующий раствор 1:10). Пробирки встряхивают 1 час, затем проводят центрифугирование. Получившийся раствор отправляют на аналитические исследования. Остаток почвы после предыдущих обработок заливают следующим экстрагирующим раствором. Химический анализ вытяжек проводился масс-спектрометрическим методом с индуктивно-связанной плазмой (ICP-MS).

Минералогический состав почв изучался методами рентгенофазового анализа и электронной микроскопии в лаборатории МИНОЦ «Урановая геология» ТПУ.

\section{Результаты и их обсуждение}

Почва является депонирующей средой, накапливающей химические элементы. Особенную значимость это приобретает в условиях длительной техногенной нагрузки [24]. Почвы Кольского полуострова достаточно хорошо исследованы в разных аспектах в связи с высоким уровнем антропогенного влияния [2, 25-27]. Установлено, что в верхних органогенных горизонтах почвы зафиксированы чрезвычайно высокие концентрации $\mathrm{Ni}$ и $\mathrm{Cu}[2,25]$. Концентрации $\mathrm{Ni}, \mathrm{Cu}$, $\mathrm{Cd}, \mathrm{Pb}$, и Со в верхнем горизонте почвы выше, чем в иллювиальном [2]. Это говорит о том, что данные химические элементы поступают из загрязненной атмосферы $[2,8,28,29]$.
В сравнении с кларками верхней части континентальной коры, по А. Ярошевскому [30], для рассматриваемых почв наблюдается пониженное содержание большинства элементов, в том числе редкоземельных Исключения составляют $\mathrm{Br}$, I и $\mathrm{Cl}$, что объясняется близостью моря, а также $\mathrm{Te}, \mathrm{Se}$ - элементы, которые попутно извлекают из медно-никелевой руды (табл. 1).

Таблица 1. Значения коэффициентов концентраций химических элементов в почве относительно кларков химических элементов верхней части континентальной коры по А. Ярошевскому [30]

Table 1. Values of the chemical elements concentration coefficients in the soil relative to the chemical elements clarkes of the continental crust upper part according to A. Yaroshevsky [30]

\begin{tabular}{|c|c|c|}
\hline $\begin{array}{l}\text { Пункт (рас- } \\
\text { стояние до } \\
\text { комбината) } \\
\text { Point (dis- } \\
\text { tance to the } \\
\text { enterprise) }\end{array}$ & $\begin{array}{l}\text { Почвен- } \\
\text { ный гори- } \\
\text { зонт } \\
\text { Soil hori- } \\
\text { zon }\end{array}$ & $\begin{array}{l}\text { Геохимические ряды } \\
\text { Geochemical series }\end{array}$ \\
\hline \multirow[b]{2}{*}{$\begin{array}{l}\text { CП-8/SP-8 } \\
(7 \mathrm{\kappa м} / \mathrm{km})\end{array}$} & E & $\begin{array}{l}\mathrm{Te}_{19,2}-\mathrm{Br}_{6,3}-\mathrm{Se}_{1,39}-\mathrm{Ag}_{1,22}-\mathrm{Cl}_{0,8}-\mathrm{I}_{0,65^{-}} \\
\mathrm{Cu}_{0,54}-\mathrm{As}_{0,26}-\mathrm{Pd}_{0,2}-\mathrm{Pb}_{0,17}-\mathrm{Ni}_{0,13}-\mathrm{Cd}_{0,12}\end{array}$ \\
\hline & B & 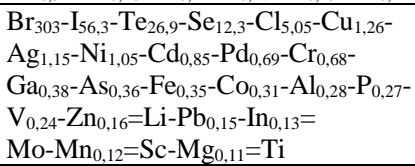 \\
\hline \multirow{4}{*}{$\begin{array}{l}\text { СП-10/SP-10 } \\
(15 \mathrm{~km} / \mathrm{km})\end{array}$} & E & $\begin{array}{l}\mathrm{Te}_{8,34}-\mathrm{Br}_{3,2}-\mathrm{Cl}_{1,49}-\mathrm{Se}_{0,9^{-}} \mathrm{I}_{0,69}-\mathrm{Ag}_{0,64^{-}} \\
\mathrm{Pb}_{0,31}-\mathrm{Cd}_{0,28}-\mathrm{Ni}_{0,21}=\mathrm{Cu}-\mathrm{Pd}_{0,2}-\mathrm{As}_{0,18}\end{array}$ \\
\hline & B1 & $\begin{array}{l}\mathrm{Br}_{72,8^{-}} \mathrm{I}_{30,1}-\mathrm{Te}_{10,6}-\mathrm{Se}_{7,03}-\mathrm{Cl}_{4,69^{-}}-\mathrm{Ag}_{0,63^{-}} \\
\mathrm{Cr}_{0,55}-\mathrm{Fe}_{0,5}-\mathrm{Ni}_{0,42}-\mathrm{P}_{0,41^{-}}-\mathrm{V}_{0,38}-\mathrm{Pd}_{0,36^{-}} \\
\mathrm{Ga}_{0,33}-\mathrm{Ti}_{0,32}-\mathrm{Cu}_{0,31}-\mathrm{Co}_{0,28}=\mathrm{Zn}-\mathrm{Cd}_{0,27^{-}} \\
\mathrm{Al}_{0,25}-\mathrm{Li}_{0,22}-\mathrm{In}_{0,2}-\mathrm{Sc}_{0,18}-\mathrm{Eu}_{0,15}= \\
\mathrm{Pb}=\mathrm{Cs}=\mathrm{As}-\mathrm{Dy}_{0,13}= \\
\mathrm{Mn}-\mathrm{Gd}_{0,12}-\mathrm{Th}_{0,11}=\mathrm{Er}=\mathrm{Tm}=\mathrm{Tb}\end{array}$ \\
\hline & B2 & 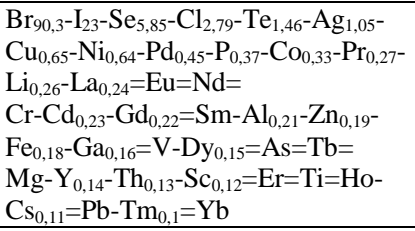 \\
\hline & C & 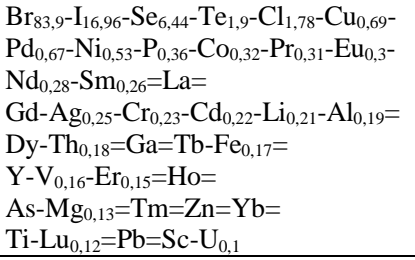 \\
\hline
\end{tabular}

Холодная местность с хорошим промывным режимом способствует формированию подзолистого горизонта Е, обедненного химическими элементами относительно других минеральных горизонтов (рис. 1).

А в иллювиальном горизонте В, согласно особенностям генетического профиля подзолистых почв, происходит концентрирование химических элементов. Это находит отражение геохимических рядах (табл. 2), где для иллювиальных горизонтов наблюдается большее количество элементов с коэффициентом концентрации $>1$ (по среднему содержанию элементов в выборке, согласно исследованиям авторов). 


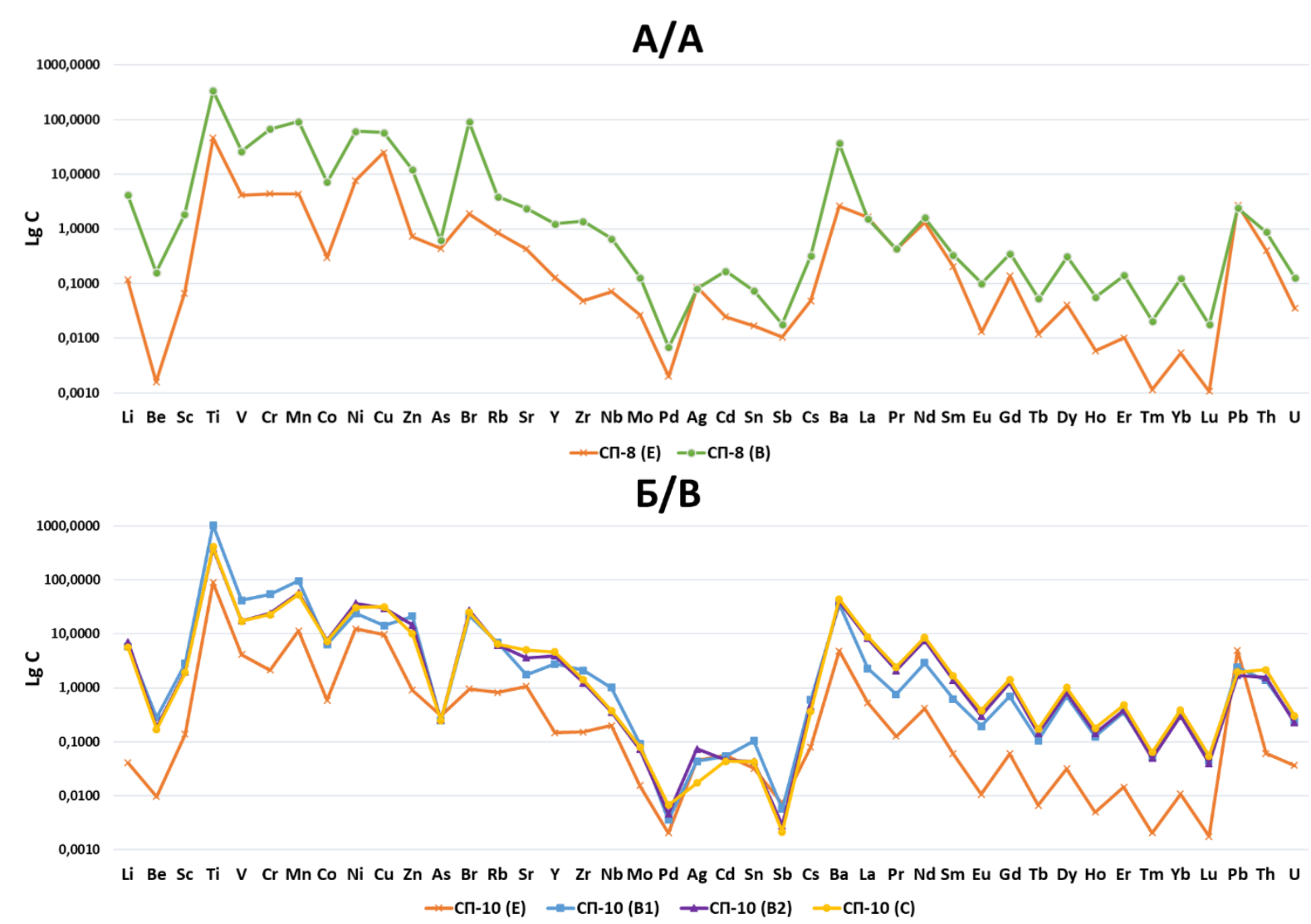

Pис. 1. Содержание химических элементов в подзолистом Е, иллювиальном В горизонтах почв и материнской породе С в пунктах опробования СП-8 (А) и СП-10 (Б) исследуемой территории (мг/кг, икала логарифмическая)

Fig. 1. Chemical elements content in E, $B$ and $C$ soil horizons in SP-8 (A) and SP-10 (B) sampling point of the study area ( $\mathrm{mg} / \mathrm{kg}$, logarithmic scale)

Таблица 2. Значения коэффициентов концентраций химических элементов в почве относительно среднего содержания элементов в выборке $(n=28)$

Table 2. Values of the chemical elements concentration coefficients in the soil relative to the average content of elements in the sample $(n=28)$

\begin{tabular}{|c|c|c|}
\hline $\begin{array}{l}\text { Пункт (расстояние } \\
\text { до комбината) } \\
\text { Point (distance to } \\
\text { the enterprise) } \\
\end{array}$ & $\begin{array}{l}\text { Почвен- } \\
\text { ный } \\
\text { горизонт } \\
\text { Soil horizon } \\
\end{array}$ & $\begin{array}{l}\text { Геохимические ряды } \\
\text { Geochemical series }\end{array}$ \\
\hline \multirow[b]{2}{*}{$\begin{array}{l}\text { CП-8/SP-8 } \\
(7 \text { км/km) }\end{array}$} & E & $\mathrm{Au}_{1,3}-\mathrm{Sb}_{1,2}=\mathrm{Re}-\mathrm{Cu}_{1,1}=\mathrm{Pb}-\mathrm{Os}_{1}$ \\
\hline & B & $\begin{array}{c}\mathrm{Cd}_{3,4}-\mathrm{Cr}_{2,6}=\mathrm{Cu}-\mathrm{Sb}_{2,1}-\mathrm{Hg}_{2}= \\
\mathrm{Ni}-\mathrm{In}_{1,8}-\mathrm{Fe}_{1,6}-\mathrm{Al}_{1,4}=\mathrm{V}= \\
\mathrm{Co}=\mathrm{Ga}=\mathrm{Ir}=\mathrm{Bi}-\mathrm{Sn}_{1,3}-\mathrm{Sc}_{1,2}= \\
\mathrm{Os}-\mathrm{As}_{1,1}=\mathrm{Au}-\mathrm{Pb}_{1}\end{array}$ \\
\hline \multirow{4}{*}{$\begin{array}{l}\text { CП-10/SP-10 } \\
(15 \text { км/km) }\end{array}$} & $\mathrm{E}$ & $\mathrm{Pb}_{2}-\mathrm{Bi}_{1,2}-\mathrm{Cd}_{1,1}$ \\
\hline & B1 & $\begin{array}{c}\mathrm{In}_{2,7^{-}} \mathrm{Au}_{2,6}-\mathrm{Ti}_{2,5}-\mathrm{Fe}_{2,3^{-}} \mathrm{V}_{2,2^{-}} \\
\mathrm{Cr}_{2,1}-\mathrm{Hg}_{2}-\mathrm{Sc}_{1,8}=\mathrm{Sn}_{-}-\mathrm{Cs}_{1,4^{-}} \\
\mathrm{Al}_{1,3}=\mathrm{Tl}-\mathrm{Co}_{1,2,2}=\mathrm{Ga}=\mathrm{Rb}_{-}-\mathrm{Li}_{1,1^{-}} \\
\mathrm{Cd}=\mathrm{Lu}-\mathrm{Mn}_{1}\end{array}$ \\
\hline & B2 & $\begin{array}{c}\mathrm{Re}_{2}-\mathrm{Tl}_{1,5}-\mathrm{Li}_{1,4}=\mathrm{Co}=\mathrm{Cu}-\mathrm{Sc}_{1,3}- \\
\mathrm{Ni}_{1,2}-\mathrm{Rb}_{1,1}=\mathrm{In}-\mathrm{Al}_{1}=\mathrm{Ba}=\mathrm{Cs}\end{array}$ \\
\hline & $\mathrm{C}$ & $\begin{array}{c}\mathrm{Tl}_{1,6}-\mathrm{Co}_{1,4}=\mathrm{Cu}- \\
\mathrm{Sc}_{1,3}=\mathrm{Lu}=\mathrm{Re}=\mathrm{Hg}- \\
\mathrm{Rb}_{1,2}=\mathrm{Y}=\mathrm{Ce}=\mathrm{Yb}- \\
\mathrm{Li}_{1,1}=\mathrm{Ba}=\mathrm{Er}=\mathrm{Tm}\end{array}$ \\
\hline
\end{tabular}

При переходе от горизонта Е к горизонту В происходит увеличение концентраций редкоземельных элементов, причем для тяжелых элементов эта разни- ца гораздо больше (может доходить почти до трех десятков раз), чем для легких.

Формирование в почвенном профиле горизонтов транзита или вымывания и аккумуляции (вмывания) веществ происходит при перераспределении химических элементов, поступающих с миграционными потоками, между растворенной, подвижной и прочносвязанной формами [11].

Однако для $\mathrm{As}, \mathrm{Cd}, \mathrm{Sb}$ и $\mathrm{Pb}$ в пункте СП-10 отмечено их преобладание в подзолистом горизонте, в отличие от пункта СП-8, что может быть связано с эродированностью здесь верхней части почвеннорастительного слоя.

Техногенное воздействие прослеживается в относительном увеличении концентраций химических элементов в 7 км от комбината (СП-8) относительно пункта в 15 км (СП-10): для горизонта $\mathrm{E}-\mathrm{Li}, \mathrm{Cr}, \mathrm{Cu}$, As, Br, Mo, Ag, Sb, La, Pr, Nd, Sm, Eu, Gd, Tb, Dy, Ho $\mathrm{Th}$; для горизонта B - V, Cr, Mn, $\mathrm{Ni}, \mathrm{Cu}, \mathrm{As}, \mathrm{Br}, \mathrm{Nb}$, Mo, Pd, Cd, Sn, Sb, Pb.

В силу особенностей природных и техногенных факторов никель и медь признаны основными элементами-загрязнителями на Северо-Западе России, как приоритетные компоненты выбросов комбинатов медно-никелевого производства [24, 29]. Их значительное концентрирование наблюдается в иллювиальном горизонте в 7 км от источника пылегазовых выбросов (рис. 2). 

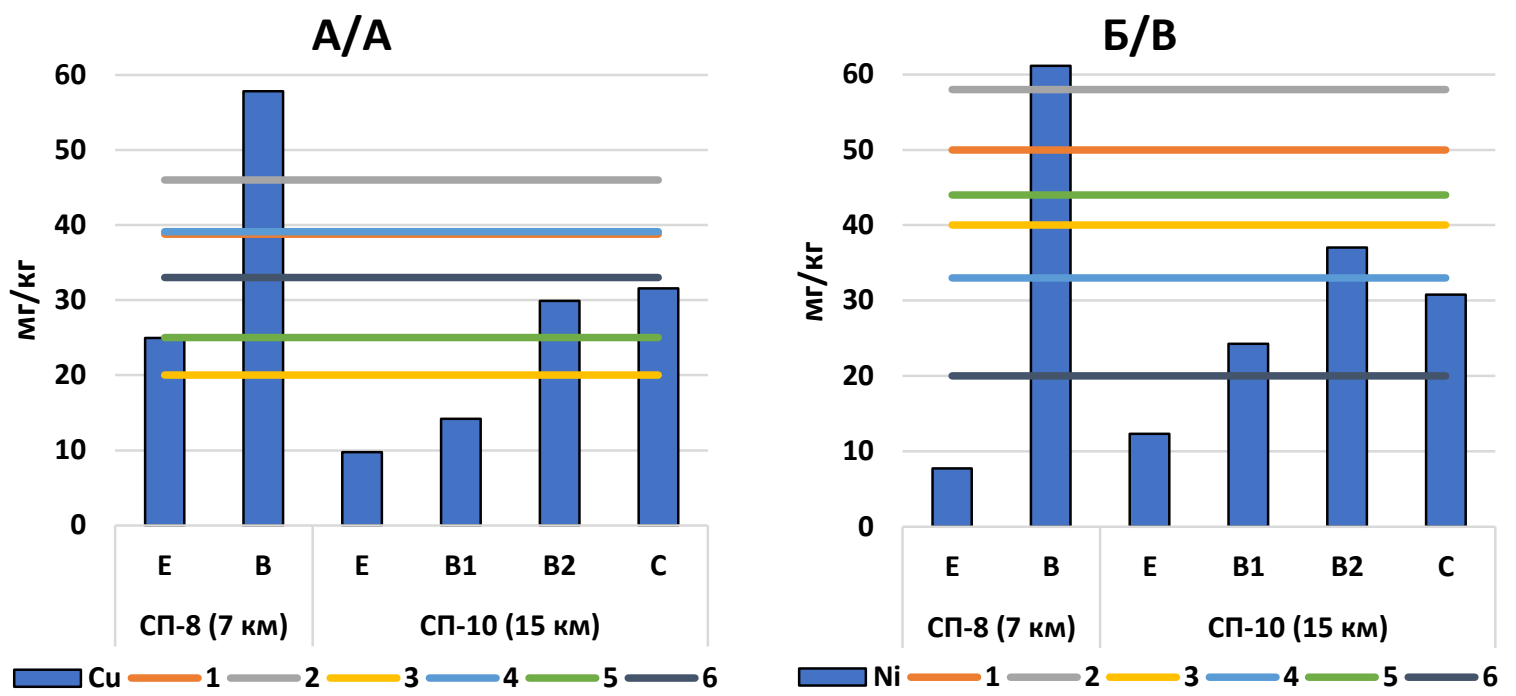

Рис. 2. Сопоставление кониентраций меди (А) и никеля (Б) в исследуемых почвах с: 1 - средним содержанием 6 верхней части континентальной коры по Н. Григорьеву [31]; 2 - кларком верхней части Земной коры по А. Ярочевскому [30]; 3 - кларком почв Земли по В. Алексеенко [32]; 4 - кларком городских почв по В. Алексеенко [32]; 5 - средней концентрацией в верхней части континентальной коры по S. Taylor, S. McLennan [33] (с обновлением для никеля S. McLennan [34]); ОДК для песчаных и супесчаных почв по СанПиН 1.2.3685-21 [35]

Fig. 2. Comparison of copper $(A)$ and nickel $(B)$ concentrations in the studied soils with: 1 -average content in the upper part of the continental crust according to N. Grigoriev [31]; 2 - clarke of the upper part of the Earth's crust by A. Yaroshevsky [30]; 3 - clarke of the Earth soils according to V. Alekseenko [32]; 4 - clarke of urban soils by $V$. Alekseenko [32]; 5 - average concentration in the upper part of the continental crust by S. Taylor and S. McLennan [33] (updated for nickel by S. McLennan [34]); approximate permissible concentration for sandy and sandy loam soils according to SanPiN 1.2.3685-21 [35]

Здесь содержания меди и никеля превышают кларковые значения, в том числе ориентировочно допустимые значения (ОДК) содержания химических веществ в почвах: для меди в 1,75 раз, для $\mathrm{Ni}$ в 3,1 paza.

Согласно результатам рентгенофазового анализа, в составе исследуемых почв преобладают $\mathrm{Ca}-\mathrm{Na}-\mathrm{Mg}-\mathrm{K}$ алюмосиликаты (табл. 3). В пункте СП-10 основными минералами в составе почв являются магнезиогорнблендит, кварц и альбит. В горизонте В2 предположительно встречен титанит.

В пункте СП-8 присутствует железосодержащий актинолит, содержание которого в горизонте В составляет $43,3 \%$.

Таблица 3. Минералогический состав почв по результатам рентгенофазового анализа (процент содержания каждого минерала указан в скобках)

Table 3. Mineralogical composition of soils according to the results of X-ray phase analysis (the percent of each mineral is in parenthesis)

\begin{tabular}{|c|c|c|c|}
\hline \multirow{2}{*}{$\begin{array}{l}\text { Почвенный } \\
\text { горизонт } \\
\text { Soil horizon }\end{array}$} & \multicolumn{3}{|c|}{ Пункт (расстояние до комбината)/Point (distance to the enterprise) } \\
\hline & CП-8/SP-8 (7 км/km) & \multicolumn{2}{|c|}{ СП-10/SP-10 (15 км/km) } \\
\hline $\mathrm{E}$ & $\begin{array}{c}\text { кварц/quartz }(39,7) \\
\text { анортит/anorthite }(23,3) \\
\text { альбит/albite }(21,1) \\
\text { энстатит/enstatite }(10,5) \\
\text { актинолит/actinolite }(5,1) \\
\text { анальцим/analcime }(0,2) \\
\text { шабазит/chabazite }(0,1) \\
\end{array}$ & \multicolumn{2}{|c|}{$\begin{array}{c}\text { кварц/quartz }(40,1) \\
\text { анортит/anorthite }(26,4) \\
\text { альбит/albite }(23,5) \\
\text { магнезиогорнблендит/magnesiohornblende }(10,9) \\
\text { анальцим/analcime }(0,4)\end{array}$} \\
\hline B & $\begin{array}{l}\text { актинолит/actinolite }(43,3) \\
\text { альбит/albite }(22,1) \\
\text { анортит/anorthite }(22,0) \\
\text { кварц/quartz }(12,1) \\
\text { цеолит/zeolite }(0,4)\end{array}$ & $\begin{array}{c}\text { В1 } \\
\text { магнеззогорнблендит/magnesiohornblende } \\
(31,7) \\
\text { кварц/quartz }(25,1) \\
\text { альбит/albite }(23,6) \\
\text { микроклин/microcline }(9,8) \\
\text { клинохлор/clinochlore }(9,5) \\
\text { цеолит/zeolite }(0,3)\end{array}$ & $\begin{array}{c}\text { В2 } \\
\text { магнеззиогорнблендит magnesiohorn- } \\
\text { blende }(37,8) \\
\text { альбит/albite }(26,0) \\
\text { кварц/quartz }(16,5) \\
\text { микроклин/microcline }(8,7) \\
\text { клинохлор/clinochlore }(4,6) \\
\text { титанит/titanite }(3,1) \\
\text { форстерит/forsterite }(2,8)\end{array}$ \\
\hline $\mathrm{C}$ & - & \multicolumn{2}{|c|}{$\begin{array}{c}\text { альбит/albite }(35,4) \\
\text { магнеззиогорнблендит/magnesiohornblende }(28,5) \\
\text { кварц/quartz }(23,3) \\
\text { микроклин/microcline }(12,5) \\
\text { цеолит/zeolite }(0,2)\end{array}$} \\
\hline
\end{tabular}


Согласно [36], в исследованном районе встречены аморфные неорганические твердые фазы - гели: гидрогётит-гель, нонтронит, гидрослюда, гель гидрооксид кремния (опал) и прочее.

Микроминеральные фазы характерных химических элементов, обнаруживаемые с помощью электронной микроскопии, отражают не только природный минералогический состав почвы, но и наличие техногенного влияния. Исследование образцов показывает, что в рассматриваемых почвах наиболее часто встречаются частицы оксидов железа, титана и алюминия.

Также в подзолистом горизонте в зоне влияния комбината встречены соединения циркония.

В пункте опробования СП-8, расположенном в 7 км от источника пылегазовых выбросов, где наблюдаются максимумы валовых концентраций основных поллютантов региона (для горизонта В $\mathrm{Ni}$ 61,16 мг/кг, $\mathrm{Cu}-57,83$ мг/кг), обнаружены собственные минеральные фазы меди и никеля.

Здесь же в подзолистом горизонте почвы обнаружены частицы с содержанием редкоземельных элементов.
Оценка опасности загрязнения не ограничивается только определением валового содержания химических элементов, поскольку геохимическая подвижность и токсическое действие поллютантов определены не только их массовым поступлением, но и зависит от их форм и характера закрепления минеральными и органическими носителями [37].

Фракиионный состав. В системе соединений химических элементов почвы выделяется «матрица»- прочносвязанные соединения, которые составляют ядро системы и отражают единство почв одного генетического ряда [11]. В спектре постадийных вытяжек она соответствует остаточной фракции. Результаты эксперимента показывают, что большинство химических элементов связано в остаточной фракцией (IV). На нее в среднем приходится от 60 до 99 \% от общего содержания химических элементов.

Подвижные соединения свидетельствуют о влиянии на почвы изменяющихся внешних условий, которые обеспечивают пространственное и временное разнообразие свойств почв [11].

Так, для $\mathrm{Sr} 56-86$ \% от суммы составляет обменная фракция (II), причем для любых почвенных горизонтов (табл. 4).

Таблица 4. Распределение химических элементов по фракииям (\% от суммы всех фракций) в образиах исследуемых почв Table 4. Distribution of chemical elements by fractions (\% of the sum of all fractions) in the studied soils samples

\begin{tabular}{|c|c|c|c|c|c|c|}
\hline \multirow[b]{2}{*}{$\begin{array}{l}\text { Пункт (расстояние } \\
\text { до комбината) } \\
\text { Point (distance to } \\
\text { the enterprise) }\end{array}$} & \multirow[b]{2}{*}{$\begin{array}{l}\text { Почвенный } \\
\text { горизонт } \\
\text { Soil horizon }\end{array}$} & \multicolumn{5}{|c|}{ Фракции/Fractions } \\
\hline & & \begin{tabular}{|c|} 
I Водорас- \\
творимая \\
Water-soluble
\end{tabular} & $\begin{array}{l}\text { II Обменная } \\
\text { Exchangeable }\end{array}$ & $\begin{array}{c}\text { III Специфиче- } \\
\text { ски } \\
\text { сорбированная } \\
\text { Specifically } \\
\text { sorbed } \\
\end{array}$ & $\begin{array}{c}\text { IV Связанная } \\
\text { с органическим веществом } \\
\text { Bound to organic matter }\end{array}$ & $\begin{array}{l}\text { V Связанная с (гидр)- } \\
\text { оксидами Fe и Mn } \\
\text { Bound to Fe and Mn } \\
\text { oxides }\end{array}$ \\
\hline \multirow{2}{*}{$\begin{array}{r}\text { СП-8/SP-8 } \\
(7 \text { км/km) }\end{array}$} & $\mathrm{E}$ & $B r$ & $\begin{array}{c}\text { Be Ni Sr Rh } \\
M g M n C o C u \\
\mathrm{Se} C d B a \\
\end{array}$ & $\mathrm{Cu}$ & $\begin{array}{c}\text { Na Sc Zn Se Rb Zr Sb_Yb } \\
\text { Lu U Be Cr As Y Rh Ho Er } \\
T m P b T i M o \text { Al V Fe Dy }\end{array}$ & Mo $S c$ \\
\hline & B & - & $\mathrm{Sr} \mathrm{Cd} \mathrm{Ba}$ & $\mathrm{Cu} \mathrm{Cd} \mathrm{Ba}$ & $\begin{array}{l}\text { Rb Sb Sc Se Zr Lu U Mo Ti } \\
\text { Cr As Y La Ce Pr Nd Sm Eu } \\
\text { Gd Tb Dy Ho Er Tm Yb Pb }\end{array}$ & Mo $\mathrm{Ni}$ \\
\hline \multirow{4}{*}{$\begin{array}{l}\text { СП-10/SP-10 } \\
(15 \text { км/km) }\end{array}$} & E & - & $\begin{array}{l}\text { Co Ni Cd Mg } \\
\text { Sr } Z n B a M n\end{array}$ & $\mathrm{Cu}$ & $\begin{array}{c}\text { Sb Zn Sc Lu Na Zr Rb U } \mathbf{Z}_{-} G e \\
T e \text { Ti Er Fe Ho Cr Y Dy Pb } \\
\text { Mo Al Si }\end{array}$ & $\begin{array}{l}\text { Cu Sn } \\
\text { Mo } S i\end{array}$ \\
\hline & B1 & - & $\mathrm{Sr} \mathrm{Ba}$ & $B e$ & $\begin{array}{c}\text { Na Se Sb Rb Sc Mo U Zr Al } \\
\text { Ti Cr Zn Mn Co As Br Y I Ce } \\
\text { Pr Nd La Ho Sm Gd Eu Tb Er } \\
\text { Tm Dy Yb Lu Pb Th }\end{array}$ & Mo $\mathrm{Sn} \mathrm{Cu}$ \\
\hline & B2 & - & $\mathrm{Sr} \mathrm{Ba}$ & - & $\begin{array}{c}\text { Na Sb Rb Lu Pb U Sc Mo Zr } \\
\text { Ti Zn Ge As Br Y I Ba Pr Gd } \\
\text { Ce Sm Eu Nd Tb Dy Ho La } \\
\text { Er Yb Tm Th }\end{array}$ & Mo Cu I \\
\hline & $\mathrm{C}$ & - & $\mathrm{Sr} \mathrm{Ba}$ & $\mathrm{Be} \mathrm{Ge}$ Y Ba La & $\begin{array}{c}\text { Na Rb Zr Sb Lu Pb U Sc As } \\
\text { Se Mo Be Ti Zn Br Y I In Tb } \\
\text { Nd Sm Yb Eu Pr Gd Dy Ho } \\
\text { Er Tm Th }\end{array}$ & Sn Mo Cu I In \\
\hline
\end{tabular}

Примечание: преобладающая фракиия элементов \% от суммы всех фракций (после остаточной, т. е. вторая по величине): выделено жирным - если фракция преобладает над остаточной (т. е. эта фракция по содержанию на первом месте), курсивом - рракция занимает второе место после остаточной, но ее \% очень значителен.

Note: the predominant fraction of elements \% of the sum of all fractions (after the residual, i. e. the second largest): highlighted in bold if the fraction prevails over the residual (i. e. this fraction is in the first place in terms of content), italic-the fraction takes the second place after residual, but its \% is very significant.

Кроме остаточной фракции барий активно представлен в обменной при том, что для горизонта Е это 22-32\%, тогда как для горизонтов В и С- только 10-15\%.

Для никеля характерно преобладание обменной формы (40-60 \% от суммы всех фракций) в подзолистом горизонте Е, однако в точке СП-10 доля этого элемента, связанного с органическим веществом, возрастает до $14 \%$. Это может быть связано с сохранностью здесь подстилки и органогенного горизонта.

Для меди отмечено почти равное распределение по пяти фракциям (II-III-IV-V-VI) - от 12 до $26 \%$ от суммы всех фракций в подзолистом горизонте 
(рис. 3). В иллювиальном горизонте отмечено увеличение доли специфически сорбированной фракции (III) меди в 7 км от комбината, а в 15 км - связанной с (гидр)оксидами железа и марганца (V).

Микроэлементы, связанные с органическим веществом вследствие его относительно невысокой доли содержания и значительно меньшей устойчивости по сравнению с минеральными носителями, оказывают меньший вклад в общий уровень содержания микро- элементов в почве [11]. Однако, как видно из табл. 3, органическое вещество играет важную роль в связывании многих химических элементов (в том числе редких земель) в рассматриваемых почвах. Доказано, что фульвокислоты, как и гуминовые кислоты, формируют с лантаноидами прочные комплексные соединения [38]. Для таких элементов, как $\mathrm{Na}, \mathrm{Rb}, \mathrm{Sb}$, часто для $\mathrm{Zr}, \mathrm{Lu}, \mathrm{Pb}, \mathrm{U}$, фракция, связанная с органическим веществом, является ведущей.

\section{$\mathrm{Cu}$}

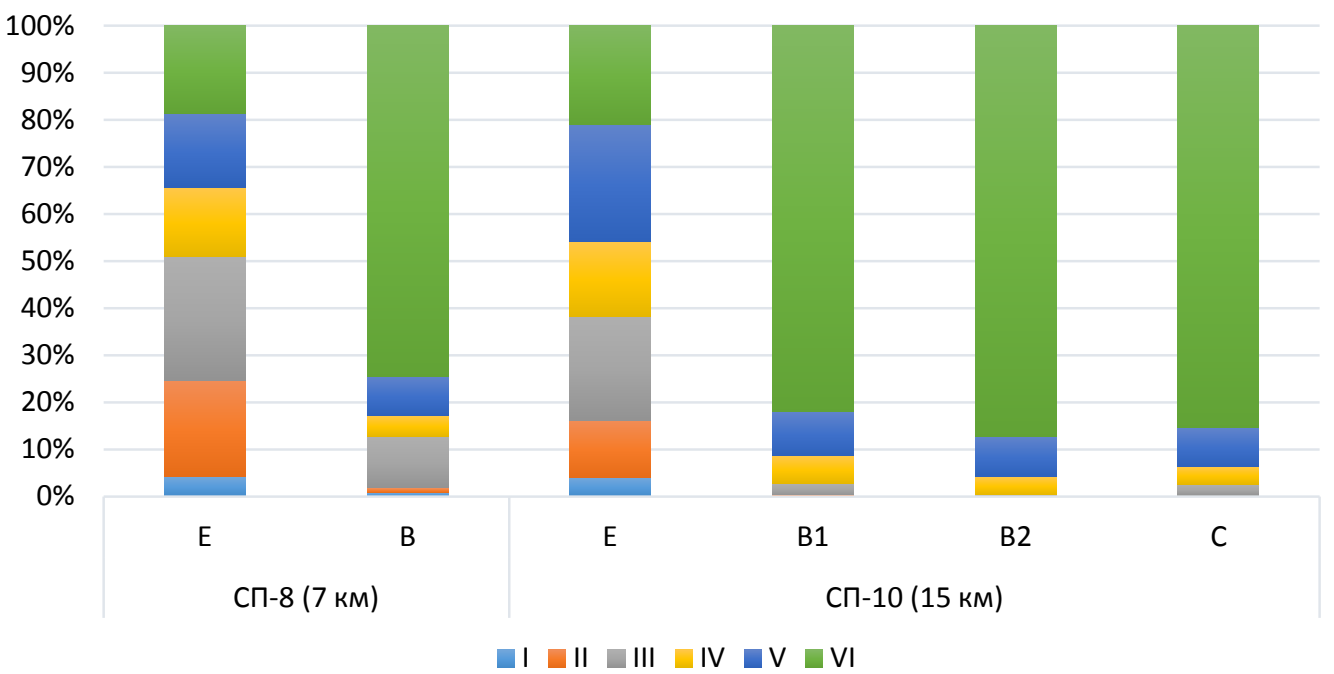

Pис. 3. Фракиионный состав меди в почвенных горизонтах (\% от суммы всех фракиий)

Fig. 3. Copper fractional composition in soil horizons (\% of the sum of all fractions)

Основная часть молибдена приходится на фракцию, связанную с оксидами и гидроксидами $\mathrm{Fe}$ и $\mathrm{Mn}$ (40-64 \%), и органическим веществом (23-31\%).

Организация системы соединений микроэлементов в загрязненных почвах - совместный результат влияния техногенных факторов и буферных свойств природной системы соединений химических элементов в почвах [11]. В рассматриваемых почвах отмечается повышение содержания $\mathrm{Co}, \mathrm{Ni}, \mathrm{Cu}, \mathrm{Cd}, \mathrm{As}, \mathrm{Sb}$ в водорастворимой форме до 3,5-14 \% в подзолистом и $1-2 \%$ в иллювиальном горизонте. Увеличение доли подвижных форм, определяющих высокую миграционную способность и биодоступность тяжелых металлов, является основным следствием техногенного загрязнения [39].

\section{Заключение}

В целом влияние выбросов медно-никелевого комбината прослеживается в увеличении концентрации меди и никеля в иллювиальном горизонте почв, превышающих ОДК, и присутствии микроминеральных фаз оксидов никеля и меди и соединений редкоземельных элементов.

\section{СПИСОК ЛИТЕРАТУРЫ}

1. Бородина Н.А., Голов В.И. Содержание различных форм $\mathrm{Cu}$, $\mathrm{Zn}$ и $\mathrm{Mn}$ в почвах города Благовещенск (Амурская область) // Вестник ДВО РАН. - 2013. - № 5. - С. 69-76.
Важное значение имеет то, что в почвах зоны интенсивного воздействия выбросов медно-никелевого производства, по сравнению с более удаленными от источника выбросов, увеличивается содержание и доля подвижных форм основных поллютантов региона - $\mathrm{Ni}$ и $\mathrm{Cu}$, а также $\mathrm{Cr}, \mathrm{Co}, \mathrm{Cd}, \mathrm{As}, \mathrm{Sb}$, и, соответственно, их биодоступность. Такое распределение микроэлементов в спектре постадийных вытяжек можно рассматривать как индикатор техногенного загрязнения окружающей среды.

На рассматриваемой территории важную роль в удержании химических элементов играет органическое вещество. С ним связана основная доля редкоземельных элементов, $\mathrm{Na}, \mathrm{Rb}, \mathrm{Sb}, \mathrm{Zr}, \mathrm{Pb}$ и $\mathrm{U}$.

Таким образом, почва является естественным буфером, связывающим химические элементы, поступающие из загрязненной атмосферы. Поэтому этап инфильтрации атмосферных осадков через почву приобретает значительную роль в формировании химического состава всех компонентов окружающей среды, включая сами почвы, растения и подземные воды.

Исследование выполнено при финансовой поддержке РФФИ в рамках научного проекта № 19-35-90077, 18-55-80015.

2. Елсукова Е.Ю., Опекунова М.Г., Опекунов А.Ю. Техногенная трансформация потоков тяжелых металлов в почвах в зоне воздействия медно-никелевого производства // Международный научно-исследовательский журнал. - 2019. - № 12-1 (90). - 
C. 118-124. URL: https://doi.org/10.23670/IRJ.2019.90.12.024 (дата обращения 15.03.2021).

3. Гусева Н.В., Воробьёва Д.А., Евтюгина 3.А. Особенности взаимодействия в системе вода-порода на территории водосбора озера Имандра (Кольский полуостров) // Известия Томского политехнического университета. Инжиниринг георесурсов. 2020. - T. 331. - № 8. - C. 177-188. URL: https://doi.org/ 10.18799/24131830/2020/8/2779 (дата обращения 15.03.2021).

4. Добровольский Г.В., Никитин Е.Д. Экология почв. Учение об экологических функциях почв. 2-е изд., уточн. и доп. - М.: Изд-во МГУ, 2012. - $412 \mathrm{c}$

5. Евтюгина 3.А., Асминг В.Э. Особенности формирования состава инфильтрационных вод в условиях аэротехногенного загрязнения // Вестник МГТУ: труды Мурманского государственного технического университета. - 2013. - Т. 16. - № 1. C. $73-80$.

6. Global mercury emissions to the atmosphere from anthropogenic and natural sources / N. Pirrone, S. Cinnirella, X. Feng, R.B. Finkelman, H.R. Friedli, J. Leaner, R. Mason, A.B. Mukherjee, G.B. Stracher, D.G. Streets, K. Telmer // Atmospheric Chemistry and Physics. - 2010. - V. 10. - P. 5951-5964. URL http://dx.doi.org/10.5194/acp-10-5951-2010 (дата обращения 15.03.2021).

7. Estimation of lead and zinc emissions from mineral exploitation based on characteristics of lead/zinc deposits in China / X. Zhang, L. Yang, Y. Li, H. Li, W. Wang, Q. Ge // Transactions of Nonferrous Metals Society of China. - 2011. - V. 21. - Iss. 11. P. 2513-2519. URL: https://doi.org/10.1016/S1003-6326(11) 61044-3 (дата обращения 15.03.2021).

8. Ettler V. Soil contamination near non-ferrous metal smelters: a review // Applied Geochemistry. - 2015. - V. 64. - P. 56-74. URL https://doi.org/10.1016/j.apgeochem.2015.09.020 (дата обращения 15.03.2021)

9. Ghayoraneh M., Qishlaqi A. Concentration, distribution and speciation of toxic metals in soils along a transect around a $\mathrm{Zn} / \mathrm{Pb}$ smelter in the northwest of Iran // Journal of Geochemical Exploration. - 2017. - V. 180. - P. 1-14. URL: https://doi.org/ 10.1016/j.gexplo.2017.05.007 (дата обращения 15.03.2021).

10. Groundwater co-contaminant behavior of arsenic and selenium at a lead and zinc smelting facility / R.T. Wilkin, T.R. Lee, D.G. Beak, R. Anderson, B. Burns // Applied Geochemistry. - 2018. - V. 89. P. 255-264. URL: https://doi.org/10.1016/j.apgeochem. 2017.12.011 (дата обращения 15.03.2021)

11. Мотузова Г.В. Соединения микроэлементов в почвах: системная организация, экологическое значение, мониторинг. 2-е. изд. - М.: Книжный дом «ЛИБРОКОМ», 2009. - 168 с.

12. Кузнецов В.А., Шимко Г.А. Метод постадийных вытяжек при геохимических исследованиях. - Минск: Наука и техника, 1990. $-65 \mathrm{c}$.

13. Characteristic of speciation of heavy metals in municipal sewage sludge of Guangzhou as fertilizer / L. Hei, P. Jin, X. Zhu, W. Ye, Y. Yan // Procedia Environmental Sciences. - 2016. - V. 31. P. 232-240. URL: https://doi.org/10.1016/j.proenv.2016.02.031 (дата обращения 15.03.2021).

14. Exposure of heavy metals in coal gangue soil, in and outside the mining area using BCR conventional and vortex assisted and single step extraction methods. Impact on orchard grass A.A. Qureshi, T.G. Kazi, J.A. Baig, M.B. Arain, H.I. Afridi // Chemosphere. - 2020. - V. 255. - 126960. URL https://doi.org/10.1016/j.chemosphere.2020.126960 (дата обращения 15.03.2021)

15. Integration of sequential extraction, chemical analysis and statistical tools for the availability risk assessment of heavy metals in sludge amended soils / S. Khadhar, A. Sdiri, A. Chekirben, R. Azouzi, A. Charef // Environmental Pollution. - 2020. - V. 263. 114543. URL: https://doi.org/10.1016/j.envpol.2020.114543 (дата обращения 15.03.2021).

16. Assessment of selective sequential extraction procedure for determining arsenic partitioning in copper slag / $\mathrm{H}$. bin Zhang, Y. zheng $\mathrm{He}$, J. jing $\mathrm{Hu}$, Y. nan Wang, H. zhen Cao, J. Zhou, G. qu. Zheng // Transactions of Nonferrous Metals Society of China (English Edition). - 2020. - V. 30 - Iss. 10. - P. 2823-2835. URL: https://doi.org/10.1016/S1003-6326(20)65424-3 (дата обращения 15.03.2021)
17. Khorasanipour M., Rashidi S. Geochemical fractionation pattern and environmental behaviour of rare earth elements (REEs) in mine wastes and mining contaminated sediments; Sarcheshmeh mine, SE of Iran // Journal of Geochemical Exploration. - 2020. V. $210 . \quad-106450$. URL: https://doi.org/10.1016/j.gexplo. 2019.106450 (дата обращения 15.03.2021).

18. Геология СССР. Т. 27. Геологическое описание. Мурманская область / под ред. П.Я. Антропова, Л.Я. Харитонова. - М.: Государственное научно-техническое издательство литературы по геологии и охране недр, 1958. - 715 с.

19. Ресурсы поверхностных вод СССР. Т. 1. Кольский полуостров / под ред. Ю.А. Елшина, В.В. Куприянова. - Л.: Гидрометеоиздат, 1970. - $700 \mathrm{c}$

20. Национальный атлас почв Российской Федерации / под ред. С.А. Шобы. - М.: Астрель: АСТ, 2011. - 632 с.

21. McLaren R.G., Crawford D.W. Studies on soil copper. 1. The fractionation of copper in soils // Journal Soil Science. - 1973. V. 24. - Iss. 2. - P. 172-181.

22. Ладонин Д.В. Методы определения фракционного состава соединений тяжёлых металлов в почвах // Теория и практика химического анализа почв / под ред. Л.А. Воробьёвой. - М.: ГEОC, 2006. - C. 293-309.

23. Федотов П.С., Спиваков Б.Я. Статистические и динамические методы фракционирования форм элементов в почвах, илах и донных отложениях // Успехи Химии. - 2008. - Т. 77. - № 7. C. 690-703.

24. Current state and dynamics of heavy metal soil pollution in Russian Federation - a review / N. Barsova, O. Yakimenko, I. Tolpeshta, G. Motuzova // Environmental Pollution. - 2019. V. 249. - P. 200-207. URL: https://doi.org/10.1016/j.envpol. 2019.03.020 (дата обращения 15.03.2021)

25. Кашулина Г.М. Экстремальное загрязнение почв выбросами медно-никелевого предприятия на Кольском полуострове // Почвоведение. - 2017. - № 7. - С. 860-873. URL: https://doi.org/10.7868/S0032180X17070036 (дата обращения 15.03.2021)

26. Кашулина Г.М. Мониторинг загрязнения почв тяжелыми металлами в окрестностях медно-никелевого предприятия на Кольском полуострове // Почвоведение. - 2018. - № 4 . C. 493-505. URL: https://doi.org/10.7868/S0032180X1804010X (дата обращения 15.03.2021).

27. Ревич Б.А. Риски здоровью населения в «горячих точках» от химического загрязнения Арктического макрорегиона // Проблемы прогнозирования. - 2020. - № 2 (179). - С. 148-157.

28. Evseev A.V., Krasovskaya T.M. Toxic metals in soils of the Russian North // Journal of Geochemical Exploration. - 2017. V. 174. - P. 128-131. URL: https://doi.org/10.1016/j.gexplo. 2015.05.018 (дата обращения 15.03.2021)

29. Trends and source apportionment of atmospheric heavy metals at a subarctic site during 1996-2018 / K. Kyllönen, M. Vestenius, P. Anttila, U. Makkonen, M. Aurela, I. Wängberg, M. Nerentorp Mastromonaco, H. Hakola // Atmospheric Environment. - 2020. V. 236. - 117644. URL: https://doi.org/10.1016/j.atmosenv. 2020.117644 (дата обращения 15.03.2021).

30. Ярошевский А.А. Кларки геосфер // Справочник по геохимическим поискам полезных ископаемых. - М.: Недра, 1990. C. $7-14$.

31. Григорьев Н.А. Распределение химических элементов в верхней части континентальной коры. - Екатеринбург: УрО РАН, 2009. -383 c

32. Алексеенко В.А., Алексеенко А.В. Химические элементы в геохимических системах. Кларки почв селитебных ландшафтов: монография. - Ростов н/Д: Изд-во Южного федерального университета, 2013. $-380 \mathrm{c}$

33. Taylor S.R., McLennan S.M. The continental crust: its composition and evolution. - Oxford: Blackwell, 1985. - $315 \mathrm{p}$

34. McLennan S.M. Relationships between the trace element composition of sedimentary rocks and upper continental crust // Geochemistry, Geophysics, Geosystems. - 2001. - V. 2. - Iss. 4. 2000GC000109. URL: https://doi.org/10.1029/2000GC000109 (дата обращения 15.03.2021).

35. СанПиН 1.2.3685-21. Гигиенические нормативы и требования к обеспечению безопасности и (или) безвредности для человека факторов среды обитания. - М., 2021. - 496 с. 
36. Евтюгина 3.А., Копылова Ю.Г., Солдатова Е.А. Минералогический состав почв техногенных пустошей и редколесья // Экологические проблемы северных регионов и пути их решения: Тезисы докладов VII Всероссийской научной конференции с международным участием, посвященной 30-летию Института проблем промышленной экологии Севера ФИЦ КНЦ РАН и 75-летию со дня рождения доктора биологических наук, профессора В.В. Никонова. - Апатиты, 2019. - С. 19-20.

37. Водяницкий Ю.Н. Изучение тяжелых металлов в почвах. - М.: Почвенный институт им. В.В. Докучаева, 2005. - 109 с.
38. Переломов Л.В. Взаимодействие редкоземельных элементов с биотическими и абиотическими компонентами почв // Агрохимия. - 2007. - № 11. - С. 85-96.

39. Шафигуллина Г.Т., Удачин В.Н. О формах нахождения элементов в техногенных и фоновых почвах Учалинской геотехнической системы // Башкирский Химический Журнал. 2007. - № 14 (4). - C. 70-74.

Поступила 17.04.2021 г.

\section{Информация об авторах}

Воробьёва Д.А., инженер-исследователь отделения геологии Инженерной школы природных ресурсов Национального исследовательского Томского политехнического университета.

Гусева Н.B., доктор геолого-минералогических наук, заведующая кафедрой - руководитель отделения геологии на правах кафедры Инженерной школы природных ресурсов Национального исследовательского Томского политехнического университета. 
UDC 504.5:631.4:550.4-032.1

\title{
GEOCHEMICAL CHARACTERISTICS OF SOILS: A CASE STUDY OF TERRITORY WITH A HIGH AEROTECHNOGENIC LOAD
}

\author{
Daria A. Vorobeva ${ }^{1}$, \\ vorobeyda18@gmail.com \\ Natalia V. Guseva ${ }^{1}$, \\ gusevanv@tpu.ru \\ 1 National Research Tomsk Polytechnic University,
30, Lenin avenue, Tomsk, 634050, Russia.
}

The relevance of the research is caused by the fact that soil, being a connecting link between the Earth geospheres, plays an important role, both in the economic and social development of territories. Soils are of great ecological importance, going far beyond the agricultural framework, and at the same time are often influenced by technogenic factors that can lead to a change in the course of geochemical processes (as, for example, on the Kola Peninsula, where mining and metallurgical enterprises are concentrated). Therefore, the question arises about the difference in the geochemical characteristics of soils, including the fractional composition of chemical elements compounds, of technogenically transformed and background territories.

The main aim of the research is assessment of the soils geochemical specificity, including the fractional composition of chemical elements compounds, of territory with a high aerotechnogenic load.

Objects: soils of the territory with a high aerotechnogenic load (the catchment area of Lake Imandra, Kola Peninsula, Russia).

Methods. The fractional composition of chemical elements compounds in soils was determined by successive selective extracts method. Chemical analysis of the extracts was determined by an inductively coupled plasma mass-spectrometric method. The mineralogical composition of the soils was studied by $X$-ray phase analysis and electron microscopy.

Results. Studies show that most of the chemical elements remain bound in the residual fraction. But on the territory under consideration, the main share of rare earth elements, $\mathrm{Na}, \mathrm{Rb}, \mathrm{Sb}, \mathrm{Zr}, \mathrm{Pb}$, and $\mathrm{U}$, is associated with organic matter. The effect of emissions from the copper-nickel plant is reflected in increase in copper and nickel concentration in the illuvial horizon of soils, the presence of micromineral phases of nickel and copper oxides and rare-earth compounds, as well as in increase in the proportion of mobile forms of $\mathrm{Ni}$ and $\mathrm{Cu}$, $\mathrm{Cr}$, Co, Cd, As, Sb.

\section{Key words:}

Fractionation, sequential extraction, soil, aerotechnogenic load, Kola Peninsula.

The reported study was funded by RFBR, project number 19-35-90077, 18-55-80015.

\section{REFERENCES}

1. Borodina N.A., Golov V.I. Forms of occurrence of heavy metals $(\mathrm{Cu}$, $\mathrm{Zn}, \mathrm{Mn}$ ) in the anthropogenic soils of Blagoveshchensk town (Amur region). Vestnik of FEB RAS, 2013, no. 5, pp. 69-76. In Rus.

2. Elsukova E.Yu., Opekunova M.G., Opekunov A.Yu. Technogenic transformation of heavy metal streams in soils in regions under influence of copper-nickel production. International research journal, 2019, vol. 12-1 (90), pp. 118-124. In Rus. Available at: https://doi.org/10.23670/IRJ.2019.90.12.024 (accessed 15 March 2021).

3. Guseva N.V., Vorobeva D.A. Evtyugina Z.A. Features of interaction in the water-rock system: a case study of the Imandra lake catchment (the Kola peninsula). Bulletin of the Tomsk Polytechnic University. Geo Assets Engineering, 2020, vol. 331, no. 8, pp. 177-188. In Rus. Available at: https://doi.org/ 10.18799/24131830/2020/8/2779 (accessed 15 March 2021).

4. Dobrovolsky G.V., Nikitin E.D. Ekologiya pochv. Uchenie $o b$ ekologicheskikh funktsiyakh pochv [Ecology of soils. The doctrine of the ecological functions of soils]. Moscow, MSU Publ., 2012. $412 \mathrm{p}$.

5. Evtyugina Z.A., Asming V.E. Osobennosti formirovaniya sostava infiltratsionnykh vod $v$ usloviyakh aerotekhnogennogo zagryazneniya [Features of formation of the composition of infiltration water in conditions of aerotechnogenic pollution]. Vestnik MGTU, 2013, vol. 16, no. 1, pp. 73-80. In Rus.

6. Pirrone N., Cinnirella S., Feng X., Finkelman R.B., Friedli H.R., Leaner J., Mason R., Mukherjee A.B., Stracher G.B., Streets D.G., Telmer. K. Global mercury emissions to the atmosphere from anthropogenic and natural sources. Atmospheric Chemistry and Physics, 2010, vol. 10, pp. 5951-5964. Available at: http://dx.doi.org/10.5194/acp-10-5951-2010 (accessed 15 March 2021).
7. Zhang X., Yang L., Li Y., Li H., Wang W., Ge Q. Estimation of lead and zinc emissions from mineral exploitation based on characteristics of lead/zinc deposits in China. Transactions of Nonferrous Metals Society of China, 2011, vol. 21, is.11, pp. 2513-2519. Available at: https://doi.org/10.1016/S1003-6326(11)61044-3 (accessed 15 March 2021).

8. Ettler V. Soil contamination near non-ferrous metal smelters: a review. Applied Geochemistry, 2015, vol. 64, pp. 56-74. Available at: https://doi.org/10.1016/j.apgeochem.2015.09.020 (accessed 15 March 2021)

9. Ghayoraneh M., Qishlaqi A. Concentration, distribution and speciation of toxic metals in soils along a transect around a $\mathrm{Zn} / \mathrm{Pb}$ smelter in the northwest of Iran. Journal of Geochemical Exploration, 2017, vol. 180, pp. 1-14. Available at: https://doi.org/10.1016/ j.gexplo.2017.05.007 (accessed 15 March 2021).

10. Wilkin R.T., Lee T.R., Beak D.G., Anderson R., Burns B. Groundwater co-contaminant behavior of arsenic and selenium at a lead and zinc smelting facility. Applied Geochemistry, 2018, vol. 89, pp. 255-264. Available at: https://doi.org/10.1016/ j.apgeochem.2017.12.011 (accessed 15 March 2021).

11. Motuzova G.V. Soedineniya mikroelementov v pochvakh: sistemnaya organizatsiya, ekologicheskoe znachenie, monitoring [Compounds of trace elements in soils: systemic organization, ecological significance, monitoring]. $2^{\text {nd }}$ ed. Moscow, Book house «LIBROKOM» Publ., 2009. 168 p.

12. Kuznetsov V.A., Shimko G.A. Metod postadiynykh vytyazhek pri geokhimicheskikh issledovaniyakh [Stepwise method extracts in geochemical studies]. Minsk, Nauka i tekhnika Publ., 1990. 65 p.

13. Hei L., Jin P., Zhu X., Ye W., Yan Y. Characteristic of speciation of heavy metals in municipal sewage sludge of Guangzhou as fertilizer. Procedia Environmental Sciences, 2016, vol. 31, pp. 232-240. 
Available at: https://doi.org/10.1016/j.proenv.2016.02.031 (accessed 15 March 2021).

14. Qureshi A.A., Kazi T.G., Baig J.A., Arain M.B., Afridi H.I. Exposure of heavy metals in coal gangue soil, in and outside the mining area using BCR conventional and vortex assisted and single step extraction methods. Impact on orchard grass. Chemosphere, 2020 vol. 255, 126960. Available at: https://doi.org/10.1016/ j.chemosphere.2020.126960 (accessed 15 March 2021).

15. Khadhar S., Sdiri A., Chekirben A., Azouzi R., Charef A. Integration of sequential extraction, chemical analysis and statistical tools for the availability risk assessment of heavy metals in sludge amended soils. Environmental Pollution, 2020, vol. 263, 114543 Available at: https://doi.org/10.1016/j.envpol.2020.114543 (accessed 15 March 2021)

16. Zhang H. bin, He Y. zheng, Hu J. jing, Wang Y. nan, Cao H. zhen, Zhou J., Zheng G. qu. Assessment of selective sequential extraction procedure for determining arsenic partitioning in copper slag. Transactions of Nonferrous Metals Society of China (English Edition), 2020, vol. 30, Iss. 10, pp. 2823-2835. Available at: https://doi.org/10.1016/S1003-6326(20)65424-3 (accessed 15 March 2021).

17. Khorasanipour M., Rashidi S. Geochemical fractionation pattern and environmental behaviour of rare earth elements (REEs) in mine wastes and mining contaminated sediments; Sarcheshmeh mine, SE of Iran. Journal of Geochemical Exploration, 2020, vol. 210, 106450. Available at: https://doi.org/10.1016/j.gexplo. 2019.106450 (accessed 15 March 2021).

18. Geologiya SSSR. T. 27. Geologicheskoe opisanie. Murmanskaya oblast [Geology of the USSR. Vol. 27. Geological description. Murmansk region]. Eds. P.Ya. Antropov, L.Ya. Kharitonov. Moscow, State Scientific and Technical Publishing House of Literature on Geology and Mineral Protection, 1958. 715 p.

19. Resursy poverkhnostnykh vod SSSR. T. 1 Kolskiy poluostrov [Surface Water Resources of the USSR. Vol. 1. Kola Peninsula]. Ed. by Y.A. Elshin, V.V. Kupriyanov. Leningrad, Hydrometeoizdat Publ., 1970. $700 \mathrm{p}$.

20. Nacionalny atlas pochv Rossiyskoy Federatsii [National atlas of soils of the Russian Federation]. Ed. by S.A. Shoba. Moscow, Astrel: AST Publ., 2011. 632 p.

21. McLaren R.G., Crawford D.W. Studies on soil copper. 1. The fractionation of copper in soils. Journal Soil Science, 1973, vol. 24, Iss. 2, pp. 172-181.

22. Ladonin D.V. Metody opredeleniya fraktsionnogo sostava soedineniy tyazhelykh metallov v pochvakh [Methods for determining the fractional composition of heavy metal compounds in soils] Teoriya i praktika himicheskogo analiza pochv [Theory and practice of soil chemical analysis]. Ed. by L.A. Vorobyeva. Moscow, GEOS Publ., 2006. pp. 293-309.

23. Fedotov P.S., Spivakov B.Ya., Fractionation of elements in soils, sludges and sediments: batch and dynamic methods. Russian Chemical Reviews, 2008, vol. 77, no. 7, pp. 649-660. Available at: https://doi.org/10.1070/RC2008v077n07ABEH003791 (accessed 15 March 2021).

24. Barsova N., Yakimenko O., Tolpeshta I., Motuzova G. Current state and dynamics of heavy metal soil pollution in Russian Federation - a review. Environmental Pollution, 2019, vol. 249, pp. 200-207. Available at: https://doi.org/10.1016/j.envpol. 2019.03.020 (accessed 15 March 2021)

25. Kashulina G.M. Extreme pollution of soils by emissions of the copper-nickel industrial complex in the Kola peninsula. Eurasian Soil Science, 2017, vol. 50, no. 7, pp. 837-849. Available at: https://doi.org/10.1134/S1064229317070031 (accessed 15 March 2021)

26. Kashulina G.M. Monitoring of soil contamination by heavy metals in the impact zone of copper-nickel smelter on the Kola peninsula. Eurasian Soil Science, 2018, vol. 50, no. 4. pp. 467-478. Avai- lable at: https://doi.org/10.1134/S1064229318040063 (accessed 15 March 2021)

27. Revich B.A. Population health risks in the chemical pollution hotbeds of the Arctic macroregion. Studies on Russian Economic Development, 2020, vol. 31 (2), pp. 238-244.

28. Evseev A.V., Krasovskaya T.M. Toxic metals in soils of the Russian North. Journal of Geochemical Exploration, 2017, vol. 174, pp. 128-131. Available at: https://doi.org/10.1016/j. gexplo.2015.05.018 (accessed 15 March 2021).

29. Kyllönen K., Vestenius M., Anttila P., Makkonen U., Aurela M., Wängberg I., Nerentorp Mastromonaco M., Hakola H. Trends and source apportionment of atmospheric heavy metals at a subarctic site during 1996-2018. Atmospheric Environment, 2020, vol. 236, 117644. Available at: https://doi.org/10.1016/j.atmosenv. 2020.117644 (accessed 15 March 2021).

30. Yaroshevsky A.A. Klarki geosfer [Clarke of Geospheres]. Spravochnik po geokhimicheskim poiskam poleznykh iskopaemykh. [Geochemical mineral prospecting handbook]. Moscow, Nedra Publ., 1990. pp. 7-14.

31. Grigoriev N.A. Raspredelenie khimicheskikh elementov v verkhney chasti kontinentalnoy kory [Chemical element distribution in the upper continental crust]. Ekaterinburg, UB RAS Publ., 2009. 383 p.

32. Alekseenko V.A., Alekseenko A.V. Khimicheskie elementy v geokhimicheskikh sistemakh. Klarki pochv selitebnykh landshaftov [Chemical elements in geochemical systems. Clarke soils of residential landscapes]. Rostov on Don, Southern Federal University Publ., 2013. $380 \mathrm{p}$

33. Taylor S.R., McLennan S.M. The continental crust: its composition and evolution. Oxford, Blackwell Publ., 1985. 315 p.

34. McLennan S.M. Relationships between the trace element composition of sedimentary rocks and upper continental crust. Geochemistry, Geophysics, Geosystems, 2001, vol. 2, Iss. 4, 2000GC000109. Available at: https://doi.org/10.1029/ 2000GC000109 (accessed 15 March 2021).

35. SanPiN 1.2.3685-21. Gigienicheskie normativy $i$ trebovaniva $k$ obespecheniyu bezopasnosti $i$ (ili) bezvrednosti dlya cheloveka faktorov sredy obitaniya [Hygienic standards and requirements for ensuring the safety and (or) harmlessness to humans of environmental factors]. Moscow, 2021. $496 \mathrm{p}$.

36. Evtyugina Z.A., Kopylova Yu.G., Soldatova E.A. Mineralogicheskiy sostav pochv tekhnogennykh pustoshey i redkolesya [Mineralogical composition of soils of technogenic wastelands and light forests]. Ekologicheskie problemy severnykh regionov i puti $i k h$ resheniya. Tezisy dokladov VII Vserossiyskoy nauchnoy konferentsii s mezhdunarodnym uchastiem, posvyashchennoy 30-letiyu Instituta problem promyshlennoy ekologii Severa FIC KNC RAN i 75-letiyu so dnya rozhdeniya doktora biologicheskikh nauk, professora V.V. Nikonova [Ecological problems of the northern regions and ways to solve them. Abstracts of the VII AllRussian scientific conference with international participation dedicated to the $30^{\text {th }}$ anniversary of the Institute of Industrial Ecology of the North Federal Research Center of the Kola Science Center of the Russian Academy of Sciences and the $75^{\text {th }}$ birthday of Doctor of Biological Sciences, Professor V.V. Nikonov]. Apatity, 2019. pp. 19-20.

37. Vodyanitskiy Yu.N. Izuchenie tyazhelykh metallov $v$ pochvakh [Study of heavy metals in soils]. Moscow, Dokuchaev Soil Science Institute Publ., 2005. 109 p.

38. Perelomov L.V. Interactions of Rare Earth elements with biotic and abiotic soil components. Agrochemistry, 2007, no. 11, pp. 85-96. In Rus.

39. Shafigullina G.T., Udachin V.N About forms of elements in technogenic and background of Uchaly geotechnical system. Bashkir chemical journal, 2007, no. 14 (4), pp. 70-74. In Rus.

Received: 17 April 2021.

\section{Information about the authors}

Daria A. Vorobeva, research engineer, National Research Tomsk Polytechnic University.

Natalia V. Guseva, Dr. Sc., head of Division for Geology, National Research Tomsk Polytechnic University. 